\title{
BAHASA RUPA TRADISI BALI DALAM WACANA SENI RUPA KONTEMPORER
}

I Wayan Seriyoga Parta

Fakultas Bahasa dan Seni Universitas Negeri Gorontolo

\section{Abstract}

Self-educated Balinese artists develop Balinese visual art based fully on practices, diligence, and tenacity in creating their works so that they can master all the established techniques used in visual art production. Their long struggles in dealing with technical matters to process materials have enriched them with important experience and become the base of their technical knowledge. The self-creativity they possess, untouched by academic values, enable them to beat their collective unconsciousness. Thus, they can consciously create innovations in the visual language they are working on within their collective domain. This enables them to hold their own identity and to base their work on the values coming from their local culture. This kind of creativity can also play an important role in global context. On the other hand, many contemporary artists including istallation and textile artists have conducted a kind of critical reflection upon the social condition in which they live. The above situation creates optimism that the potential of the visual art in Balinese tradition may give various colors on the development of contemporary visual art.

Keywords: creativity, self-educated, the visual art in traditons, and contemporary visual art

\section{PENDAHULUAN}

Tradisi adalah sebuah konsep untuk meletakkan nilai-nilai kultural yang ada di masyarakat yang diwarisi secara turun-temurun, kategori tradisi dihadirkan sebagai kutub yang cenderung berlawanan dengan kemodernan. Tradisi dianggap mewakili kebudayaan yang stagnan, statis, maka dari itu cenderung dianggap menghambat usaha untuk mengejar kemajuan dan progres yang terus-menerus merupakan semangat modern. Akan tetapi dalam kenyataannya tradisi pada berbagai kebudayaan senantiasa mengalami dinamika dan evolusi, dikarenakan berbagai aspek dan perubahan sosial, budaya yang mempengaruhi masyarakat pendukungnya. 
Kebudayaan Bali yang sejak lama dikatakan memiliki akar yang kuat dan terus tumbuh seiring dengan perkembangan zaman. Baik sejak mengalam persinggungan dengan kebudayaan Barat di awal abad ke-20 khususnya di Bal Selatan, yang kemudian meletakkan konstruksi pada kesadaran akan nilai-nila luhur identitas budaya Bali dalam kerangka pariwisata budaya. Pun disaat modernitas semakin kencang mendera dalam perkembangan pariwisata di Bali, kebudayaan tradisi kemudian mengalami diversikasi. Berupa pemisahan antara kepentingan religi dan kepentingan industri pariwisata, pemisahan tersebut tentunya tidak berjalan dengan damai namun penuh dengan dinamika sehingga pada akhirnya melahirkan konvensi tersebut.

Tradisi dan modernitas menjadi dua entitas penting dalam kebertahanan dan perkembangan kebudayaan Bali, kondisi yang lebih real dapat dilihat dalam perkembangan kesenian khususnya seni rupa. Pada masa pra-modernitas, masyarakat Bali pada umumnya telah biasa dengan aktivitas seni namun belum memiliki kesadaran seni dan keprofesian, atau kesadaran sebagai individu seniman. Berkarya (melukis) mereka jalani sama seperti halnya ketika ngayah membuat gambar pewayangan langit-langit, mengukir relief pada bangunan pura, membuat patung perwujudan dewa-dewa. Seni rupa Bali pra modern sangat terkai dengan entitas agama-Hindu seni merupakan bagian inheren kehidupan keagamaan. Spirit ngayah mendasari aktivitas seni masyarakat Bali pada umumnya dan tidak ada keterpisahan antara akivitas seni sebagai aktivitas budaya dan aktivitas religi. Hal ini terepresentasi dalam tema-tema yang mereka angkat umumnya adalah diseputar epos Mahabarata dan Ramayana, Tantri, serta cerita lainnya dalam kitab suci Hindu.

Kehadiran Pitamaha tahun 1937 yang dibentuk oleh Cokorda Gede Raka Sukawati dengan Walter Spies dan Rodelf Bonnet. Hadir sebagai sebuah organisasi yang mewadahi aktivitas pelukis dan pematung Bali pada waktu itu, memberikan kontribusi pada bidang pemasaran karya seni. Lembaga ini bertugas mengumpulkan karya-karya seniman Ubud, Gianyar, Sanur dan Denpasar serta memfasilitasi dalam penyelenggaraan pameran dan juga mencari pemasaran karya. Melalui Pitamaha inilah nilai-nilai identitas-estetik seni lukis Bali dan kesadaran senimannya mulai terbangun, maka secara perlahan hadirlah personalpersonal yang kemudian mulai terkukuhkan posisinya sebagai individu seniman.

Seiring dengan perkembangan zaman, para seniman yang berkarya dalam jalur yang kemudian disebut tradisi dan belajar secara otodidak, dan lambat laun karya-karyanya juga mengalami perkembangan. Perkembangan zaman (modernisasi) memberi dampak sangat besar dalam membentuk sikap dan persepsi mereka untuk memaknai tradisi, kedirian, dan modernitas. Jika umumnya seniman yang tumbuh dari latar akademisme memakai ideom (bahasa) sen modern untuk memaknai tradisi mereka, maka para seniman yang tumbuh dar tradisi justru merevitalisasi bahasa tradisi untuk memaknai perubahan akibat dari modernitas yang dialami.

Tradisi sebagai bahasa rupa bagi mereka adalah sama kedudukannya, dan bahkan memiliki nilai yang khas yang membedakan mereka dari seniman akademis. Para seniman otodidak mengembangkan gagasan mereka dengan bahasa rupa yang dikembangkan dari bahasa rupa tradisi. Primadi Tabrani (2005) meneliti mengenai bahasa rupa sejak dari tahun 1970-an mengungkapkan kekhasan bahasa rupa tradisi adalah "pada cara wimba". Bahasa rupa tradisi khususnya di Bali masih terus diwarisi hingga saat ini, dan bahkan juga mengalami perkembangan. Perkembangan tersebut dapat dilihat pada sosok seniman-seniman yang dibahas dalam kajian ini. Perkembangan kekaryaan mereka bukan hanya merupakan fenomena visual semata, namun juga ada basis pengetahuan (knowledge) yang bekerja di dalamnya, sebuah kesadaran pembelajaran yang berbeda dari ranah akademis yang terstruktur dalam kurikulum.

Pembelajaran di balik proses kreasi mereka adalah sebuah fenomena yang menarik untuk dikaji, pembahasan ini merupakan sebuah kajian pada para seniman otodidak yang mengembangkan kreativitas kekaryaan mereka yang berbasis pada bahasa rupa tradisi. Para seniman yang berkarya seni patung dan juga seni lukis dan yang juga berkarya keduanya, mereka dipilih berdasarkan pengembangan pengetahuan teknik (technical knowledge), yang berbasis bahasa rupa tradisi yang telah dilakukan selama puluhan tahun. Lebih lanjut, kajian ini juga mencoba untuk memetakan eksistensi mereka dalam wacana seni rupa kontemporer.

\section{KARYA DAN PROSES KREASI SENIMAN OTODIDAK}

Seniman Bali yang belajar secara otodidak mengembangkan seni rupa Bali yang sepenuhnya berbasis pada praktek, dengan ketekunan dan keuletan dalam berkarya sehingga memiliki penguasaan teknik yang matang. Berdasarkan pengetahuan dasar berupa kecakapan teknik dan nilai-nilai filosofi yang besumber dari ajaran Hindu Bali, mereka kemudian mengembangkan gaya ungkap pribadi dalam karya seni masing-masing. Kreativitas berkarya yang mereka jalani berdasarkan pada pengembangan kemampuan pengornanisasian skill untuk mengolah material, dalam istilah neurosisnya disebut sebagai motor memory (procedural).

Bentuk pengetahuan yang cenderung berbeda dengan pengetahun berbasis kognitif yang lebih menitik beratkan pada penemuan teoritis. Mereka bisa sampai membuat bentuk yang realis bukan karena mempelajari struktur tubuh; mulai tulang, otot yang ketat dalam ilmu anatomi tubuh. Pembelajaran melukis oleh mereka sangat empiris dan sekaligus juga imajinatif, mendasarkan pada penyerapan dengan indra mata, dimulai dengan nempe (mencontoh) pada seorang guru pada akhirnya mereka mengambangkan imajinasinya hingga menemukan bahasa ungkapnya sendiri. 
Pengalaman lebih menempa perjalanan kreativitas mereka dari pada pengetahuan dan wawasan teoritik. Intuisi atau kesadaran dalam persaingan, kemudian menuntun mereka untuk mengembangkan karakter dan gaya masingmasing, yang tumbuh dari intuisi tentang eksistensi diri dalam persaingan kolektif. Melalui latar belakang kreativitas itu, mereka lahir sebagai master-master yang memiliki kecakapan dalam olah material, serta didukung dengan sensibilitas (kinesthetic sensitivity) untuk mengolah unsur-unsur visual menjadikan mereka mampu melahirkan karya yang bernilai tinggi secara artistik dan estetik.

Pergulatan panjang dalam bergumul dengan hal-hal teknis dan mengolah material merupakan pengalaman penting yang menjadi basis pengetahuan emperis (technical knowledge), untuk melahirkan karya seni dengan penghayatan mendalam yang sarat dengan nilai artistik dan nilai filosofis. Seperti halnya proses kreatif I Ketut Muja yang berkarya tanpa memakai sketsa terlebih dahulu, sketsa baginya berada dalam imajinasi dan hadir ketika berhadapan dengan materia kayu. Tapi terkadang banyangan imajiner wujud karya yang akan dibuat tak juga hadir disaat ia ingin memulai proses untuk berkarya, sehingga tak khayal ia harus menjalani proses yang panjang bergulat dengan kayu untuk melahirkan ide karya yang akan dihasilkan dari material itu.

Dalam kesempatan lain, sering kali ide imajiner sudah hadir secara langsung ketika ia menemukan sebuah material kayu, dan ia pun segera bergegas mengambil pahatnya untuk mewujudkannya pada bahan yang baru ditemukan. Dituntun oleh imajinasinya dengan penuh semangat Ketut Muja terus mengayunkan pengotoknya (palu untuk mengukir) mengarahkan pahatnya dan secara perlahan bentuk pun mulai mewujud pada media kayu yang dikerjakan.

Kreativitas yang sama juga dilakoni oleh Made Sama, dengan lebih menitik beratkan pada eksplorasi serat kayu, karya-karya patungnya mengetengahkan bentuk-bentuk yang mengikuti alur dari serat kayu. Proses berkarya yang dijalaninya juga terbilang cukup unik, untuk membuat sebuah bentuk karya ia terlabih dahulu harus mempelajari serat kayu. Terkadang material kayu yang telah ditemukan akan dibiarkan teronggok di studio dalam waktu bertahun-tahun lamanya, karena belum berhasil menemukan karakter bentuk yang pas dengan material tersebut. Kayu memiliki karakter serat yang berbeda-beda karena itu diperlukan kejelian untuk mengenali karakter kayu yang akan dipaka sebagai karya, namun tak jarang Made Sama menemukan serat yang kompleks pada material kayu tertentu sehingga bentuk yang sebelumnya sudah jelas tergambar dalam imajinasinya terkadang harus dikompromi ketika berhadapan dengan material.

Pematung I Made Sukanta Wahyu juga berkarya dengan merespon bentuk kayu yang dia temukan untuk merealisasikan bentuk-bentuk yang lebih imajiner, ia sering kali sudah melihat bentuk karyanya pada material yang ditemukan, dalam penuturannya "kayu sebetulnya bukan hanya berupa material fisik semata karena di dalamnya juga ada semacam roh yang dapat diajak berkomunikasi, bagi yang memiliki kepekaan supranatural". Sebagian besar karya-karya Made Sukanta Wahyu yang juga seorang pemangku (pendeta) memang mengetengahkan aura mistis, merupakan hasil eksplorasi dan komunikasinya dengan material kayu yang dipakai. Untuk mendukung karakter mistis tersebut, juga didukung dengan pemilihan teknik finishing yang pas, dengan teknik membakar kayu sehingga menghasilkan efek warna gelap yang kemudian direspon dengan bahan lainnya seperti bedak. Menurutnya setiap benda di alam pasti memiliki energi, dan energi inilah yang kemudian menjadi spirit baginya untuk berkarya.

Fenomena yang menarik dari kecenderungan ketiga seniman yang menggeluti seni patung ini, adalah sistem kerja yang berada dalam ranah imaji. Sebuah proses yang menarik dikaji lebih lanjut nantinya, karena mereka umumnya tidak melakukan studi bentuk atau desain terlebih dahulu, ide tentang bentuk itu muncul ketika mereka berhadapan dengan material kayu. Ide muncul seketika atau dalam proses perenungan dengan bahan, ketika sudah ketemu ide yang akan dibuat bentuk kemudian muncul dalam kayu tersebut sesuai dengan imajinasi mereka. Kinerja kreatif ini merupakan salah satu basis pengetahuan (knowledge) yang khas dari para seniman otodidak, yang dalam dunia akademis kerap digolongkan tidak ilmiah.

Fenomena lain yang menarik dari seniman patung, ternyata tidak hanya mengeluti satu bidang saja IB. Alit selain membuat patung juga melukis, secara kebentukan patungnya terlihat biasa, namun dalam finishing ia menerapkan teknik melukis pada permukaan patung dengan cat akrilik. Kreativitasnya dalam medium seni lukis menjadi stimulus untuk mengembangkan teknik finishing karya seni patung. Dalam karya seni lukisnya IB. Alit menggabungkan elemen-elemen dari bentuk-bentuk tradisi seperti patung dan bentuk pewayangan dengan warna yang beragam dan cenderung cerah. IB. Alit berusaha mengaktualisasikan bahasa rupa tradisi dengan kecenderungan visual yang bersifat kekinian, yang salah satunya dicirikan dengan pemakaian warna-warna cerah tanpa campuran. Ia mengangkat nilai ornamentik dalam tradisi seni dekoratif dijadikan elemen visual yang sesusi dengan perkembangan rupa kontemporer.

Dalam mengembangkan karya-karyanya Gus Alit pun terus mencoba mengeksplorasi medium dan material seni rupa lainnya, belakangan ini dia tengah mencoba menggabungkan ketertarikan barunya pada medium fotografi dengan karya-karyanya sebelumnya. Selain IB. Alit, seniman patung yang juga berkarya lukis adalah Sukanta Wahyu yang membuat kolase topeng kayu dalam kanvas dan ia juga memakai kolase benang sebagai aksen untuk karyanya.

Praksis tersebut, menunjukkan bahwa mereka tidak membatasi eksplorasi kreativitasnya hanya pada medium tertentu, kesadaran itu menjadikan mereka 
merambah keberbagai eksplorasi medium, Sukanta Wahyu bahkan juga kerap kali mambuat karya instlasi dalam pemeran-pameran yang diikutinya.

Penemuan ide karya found - idea dari material yang berupa benda-benda temuan (found object) dilakoni Ida Bagus Putu Gede Sutama, sebuah proses yang menarik karena sangat melibatkan proses penyelarasan hand - eye yang menurut Harward Risatti (A Theory of Craft) lebih lekat dengan seni rupa murni (fine art). Mata dalam hal ini berperan dalam menangkap benda-benda yang ada di sekitar untuk kemudian ditransfer ke otak untuk memikirkan ide karya apa yang cocok dengannya, dalam proses penggalian ide ini Gus Sutama banyak berkaca pada pengalaman sosial budaya yang dialaminya. Setelah ide wujud karya ditetapkan baru kemudian kinesthetic sensibility mendukung dalam merespon wujud karya yang diinginkan.

Found object atau ready made adalah karya seni yang direkonstruksi dari benda-benda termuan atau barang- barang jadi, yang kemudian diberikan makna baru dalam konteks karya seni. Karya-karya semacam ini banyak dilakoni dalam perkembangan Dada dan Surrealisme dengan tokohnya antara lain Marcel Duchamp dengan karya urionir yang diberikan title R.Mutt dan Mann Ray.

Melalui karya found object itu Gus Sutama merefleksikan kegelisahannya tentang tanda dan makna kebudayaan, dan lebih lanjut tentang pemaknaan budaya tradisi dalam konteks kekinian. Kreativitas yang dilakoni Gus Sutama tidak hanya sekedar merekonstruksi benda-benda temuan menjadi karya dengan pemaknaan baru, dengan mempertahankan bentuk aslinya ia juga sedang mendokumentasi kembali warisan-warisan kebudayaan masa lalu. Rekam jejak dalam artefakartefak tersebut sekaligus memberikan sebuah pembelajaran mengenai sejarah kebudayaan, Gus Sutama menampilkan kembali arketif-artketif masa lalu dengan bentuknya yang artistik dan nilai makna baru sesuai dengan konteks persoalan masa kini. Proses kreativitas tersebut tidaklah mudah, karena harus menyelaraskan sensibilitas artistik dengan konsepsi yang ditopang dengan wawasan kebudayaan.

Para seniman (yang berkreasi secara otodidak) ini mengawali kreativitas berkarya dengan beranjak dari bahasa rupa tradisi, sejak kecil mereka sudah belajar mengukir atau belajar membuat patung, menggambar wayang secara nyantrik dari para pendahulu. Dari proses itulah mereka belajar teknik-teknik yang menjadi bekal untuk mengembangkan bahasa rupa dengan ekspresi pribadi. Mereka tidak mau berhenti hanya mengulang-ulang seni rupa yang diwarisi secara kolektif, mereka juga mengembangkan pergaulan dengan seniman-seniman lebih muda yang umumnya mempunyai latar akademis melalui wahana pameran yang diikuti. Pergesekan tersebut, melahirkan energi baru yang membuat mereka lebih intensif mengembangkan bahasa rupa dengan nilai ungkap pribadi. Bahasa rupa tersebut masih memiliki keterkaitan dengan bahasa rupa tradisi, yang dikembangkan dengan sentuhan kreasi dan inovasi untuk menyesuaikan dengan nilai-nilai yang kontekstual dengan zamannya.

Made Budi sejak tahun 1970-an sudah mengembangkan gaya tersendiri dari seni lukis Batuan yang sebelumnya sudah dikembangkan oleh pendahulunya Made Djata ditahun 1930-an mulai diperkenalkan dengan material, dan karya lukis dari Barat oleh antropolog Margaret Mead. Made Budi mengembangkan gaya naturalis dengan tema-tema tentang Bali sebagai sebuah destinasi pariwisata, kondisi-kondisi modernitas yang dia jalani sebagai bagian dari masyarakat Bali ditampilkan secara unik dengan bahasa rupa tradisi. Pengembangan yang signifikan terhadap bahasa rupa tradisi dalam kekaryaan Budi adalah penyerapannya terhadap perspektif, terutama dengan perspektif burung dan komposisi yang memenuhi kanvas.

Perkembangan yang berbeda terjadi pada kekaryaan alharmun Dewa Putu Mokoh dari Pengosekan Ubud, melukis dengan gaya khas yang naif seperti gaya melukis anak-anak. Keunikannya yang lain dapat dilihat dalam beberapa seri karya "Kain" yang dibuat di tahun 2000an yang hanya menampilkan kain yang sedang digantung. Sepintas karyanya mungkin terlihat biasa-biasa saja namun dalam amatan penulis karya ini memperlihatkan kecenderungan Mokoh pada kesadaran komposisional. Karya-karya tradisional Bali pada umumnya memakai komposisi yang cenderung penuh untuk menampilkan narasi secara utuh dalam satu bidang karya. Mokoh melampui konvensi tersebut dengan menampilkan obyek secara bersahaja dengan posisi dipinggir kiri dan bidang yang lain dia biarkan kosong, bidang yang dapat diasosiasikan sebagai langit. Komposisi dalam karya Mokoh bukan semata untuk menampilkan narasi, kesadaran untuk mengeksplorasi aspek-aspek formal yang lebih intens.

I Ketut Santosa dengan berani memakai karakter wayang untuk menampilkan persoalan-persoalan yang tengah terjadi dalam masyarakat. Karya Santosa memperlihatkan kekuatan ideom wayang yang berasal dari masa lalu, untuk berkomunikasi dengan nilai-nilai kekinian (kontemporer). Melalui ideom inovatif itu Santosa menampilkan kritik sosial dengan cara yang eklektik pada medium seni lukis kaca yang diwarisi dari leluhurnya di Nagesepaha Buleleng. Ia menggabungkan tokoh-tokoh dari pewayangan seperti tokoh punakawan SangutDelem, dengan figur manusia masa kini untuk menampilkan persoalan-persoalan kekinian di masyarakat. Ia melakukan terobosan bahasa rupa, dengan menggabungkan ideom bahasa rupa wayang dengan bahasa rupa figuratif untuk mengekspresikan kegelisahannya tentang kondisi sosial budaya di sekitarnya.

Seniman berikutnya adalah Wayan Sadha yang lebih dikenal sebagai kartunis, karya-karyanya sarat dengan muatan kritis terhadap fenomena sosial di masyarakat. Sadha mengembangkan karakter karikatur dengan penutur seekor anjing bernama Sompret, berdasarkan pada penguasaan karakter wayang yang sejak lama telah dipelajarinya. Ekplorasi karyanya pada medium kertas 
dipublikasikan melalui media massa dan majalah kebudayaan dalam rubrik karikatur ataupun karya ilustrasi, Sadha tidak hanya berhenti hanya menanggap persoalan-persoalan sosial budaya secara kritis dalam wujud rupa karikatur semata.

Wayan Sadha sebagai otodidak sejati tidak hanya berhenti mengambar, kebiasaannya bertutur dengan rupa dan teks, membuatnya juga cukup inten dalam membuat karya cerpen dan novel yang sarat dengan muatan tanggapan pribadinya perihal diri terhadap kondisi sosial masyarakat. Di balik kesederhanaan hidupnya, ia bergaul dengan berbagai kalangan dari orang biasa hingga intelektual, ha tersebut membuatnya mempunyai kepekaan sosial dan dengan kemampuan artistik dalam berolah rupa dengan garis, membuatnya fasih dalam menampilkan ide-ide kreatif ke dalam karyanya.

Perihal potensi gambar sebagai media dalam menampilkan muatan kritik sosial, juga dieksplorasi oleh Dewa Putu Kantor dengan menggali kembali dar cerita-cerita tradisi Hindu Bali untuk ditampilkan kembali sebagai metafor untuk mengungkapkan persoalan sosial yang dirasakannya. Dewa Putu Kantor yang belajar seni lukis dari gaya Batuan dalam pencarian kreatifnya ia sampai pada mengeksplorasi kebersahajaan dan kekuatan garis, yang sebelumnya dikembangkan oleh Gusti Nyoman Lempad. Dewa Putu Kantor kerap mengetengahkan tema-tema fenomena keseharian, kerap kali dia mengangka kembali cerita-cerita rakyat yang kontekstual dengan kondisi kekinian.

Dalam karyanya yang salah satu berjudul "Pan Paluk", penulis menyoroti aspek cara pengungkapnnya yang memberikan penekanan pada sosok Pan Paluk yang besar dengan kemaluan yang besar pula. Penekanan tersebut memilik intensitas tertentu umumnya merupakan tokoh yang diutamakan atau yang dipentingkan, dapat dibandingkan dengan karya-karya prasejarah terutama dalam karya seni lukis Mesir selalu terdapat sosok yang lebih besar dari obyek-obyek lainnya. Tokoh yang dibesarkan tersebut menyiratkan kedudukannya sebaga pemimpin atau raja, dalam karyanya Dewa Kantor juga tengah mengangkat kembali kecenderungan bahasa rupa prasejarah yang telah lama dilupakan tersebut.

Karya-karya seni lukis yang dikembangkan para seniman otodidak Bali menampilkan garis pada obyek lukisan (outline), mereka mengeksploras kekuatan garis yang menjadi ciri dalam seni lukis tradisi (Bali) untuk menerjemahkan ide-ide kreatif. Garis dalam karya-karya yang menggunakan bahasa rupa modern khususnya karya realis, dipakai hanya sebagai studi bentuk atau desain awal dalam proses berkarya. Sehingga kerap dikatakan sebagai gambar (drawing) atau menggambar yang kemudian dibedakan dengan lukis (painting) atau melukis yang memakai cat minyak atau cat air. Kehadiran outline sanga diminimalisir dalam karya realis karena dapat menganggu upaya untuk menampilkan realitas serealis (semirip) mungkin pada bidang lukisan. Garis membatasi upaya menampilkan volumetris atau kesan tiga dimensi pada obyekobyek lukisan realis, karena garis menjadikan karya terlihat pipih atau dua dimensi.

Fenomena yang berbeda, terjadi pada seniman yang mengembangkan bahasa rupa tradisi yang menempatkan garis sebagai elemen utama dalam karya mereka. Hal ini disebabkan karena mereka bertolak dari bahasa rupa tradisi seperti seni wayang yang umumnya pipih. Karya-karya tradisi pewayangan pada umumnya menampilkan cerita-cerita dalam epos Mahabaratha, Ramayana, atau Tantri, dalam perkembangannya oleh para seniman yang telah dibahas dalam kajian ini menunjukkan terjadinya pergeseran. Bergeser dari tema religi menjadi tema keseharian berupa pengalaman pribadi dan pengalaman sosial, yang ditampilkan melalui bahasa rupa dengan gaya ungkap yang khas oleh masingmasing seniman.

\section{BAHASA RUPA TRADISI BALI DALAM WACANA SENI RUPA}

\section{KONTEMPORER}

Dari pemaparan terhadap ke sepuluh seniman yang dikaji dalam pembahasan, menunjukkan bahwa kreativitas inovatif yang telah mereka lakukan dekat dengan semangat inovasi dan ekpresi individualitas yang lekat dalam karya seni rupa modern. Namun pembacaan terhadap kreativitas yang mereka lakoni lebih banyak dibaca sebagai hasil dari material culture (artefak kebudayaan), yang bertumpu pada pembacaan antropologi dan etnografi, artinya karya-karya mereka tidak dianggap sebagai karya seni dalam konstelasi seni rupa Modern.

Dalam lingkup material culture karya seni rupa adalah bagian dari entitas kebudayaan, persepsi inilah yang ditentang oleh semangat avantgarde seni rupa modern yang menginginkan seni rupa memiliki otonomi sendiri dengan terobosan-terobosan instrinsik dan pencapain estetik yang memiliki otentisitas. Seni rupa modern khususnya di Barat berkembang tidak saja dalam semangat otonomi penciptaan, namun juga menjelma menjadi institusi yang disebut institution of modern art yang terdiri dari; museum, art critigue, art theories, art auction dan gallery dalam kerangka institusi inilah nilai seni rupa dikonstruksi, dan institusi juga menentukan mana yang layak disebut sebagai seni dan bukan seni.

Berdasarkan paramater tersebut institusi seni rupa modern menetapkan standar yang tinggi terhadap karya-karya yang dapat digolongkan sebagai karya seni rupa (modern). Dalam seni rupa modern dapat dilihat pemisahan yang dikotomis antara fine art yang pada awalnya hanya mencangkup seni lukis, seni patung dan seni grafis pada pekembangan selanjutnya dimasukkan arsitektur dan craft yang digolongkan sebagai applied art, serta terlebih lagi seni tradisional (folk 
art) yang dikategorikan sebagai artefak kebudayaan (material culture). Berkaca dari dikotomi tersebut, maka pembahasan seni rupa di luar mainstream Barat jelas akan mengalami persoalan jika diletakkan pada kerangka Modernisme Barat.

Persoalan akan muncul "ketika seni rupa modern Indonesia hendak didudukkan dalam konstelasi seni rupa modern dunia, sebab pemegang kekuasaan adalah art world seni rupa modern Barat"(Irianto, 2000). Asmudjo J. Irianto menegaskan, "persoalan menjadi lain jika identifikasi terhadap apa yang disebu sebagai seni modern itu menyangkut wacana, teori, pengakuan,serta dominasi dan hegemoni yang terjadi dalam menentukan inklusinya”. (Irianto,2000) Dalam ha ini, Hans Belting menjelaskan bahwa paradigma modernisme (Barat) selama ini memakai standar ganda;

The definition of modern art however, was based on a double exclusion. First, the paradigm was reserved for Western art whose confines were to remain clean and protected. 'Making art' was tantamount to 'making modern art.' Artists unwilling or unable to follow this axiom, did not fall under the category of art at all. But even those who were modern in their art but lived outside the West, were not admitted to the ranks of official art history (Belting, 2009).

Dikotomi seni rupa Modern (M kapital untuk menandai mainstream oleh Eropa dan Amerika) ternyata tidak hanya pada craft dan seni tradisi, namun jug pada seni rupa modern di luar Barat yang tumbuh dari modernitas berasal dari Barat dan bersentuhan dengan konteks-konteks lokal. Sebuah pengalaman yang pernah dialami langsung oleh seni rupa modern Indonesia adalah pada pameran KIAS tahun 1991-1992, saat itu karya-karya seni modern Indonesia ditolak untuk berpameran di Museum Seni Rupa Modern di Amerika. Hal itu disebabkan karena bagi medan seni di sana karya-karya seni dari luar Barat sudah mendapat tempat di Museum Etnologi, tidak sepadan dengan karya-karya seni modern.

Memang tak dapat ditampikkan bahwa nilai-nilai lokalitas seperti; tradisi dan spiritualitas, menjadi dasar dan pijakan dalam proses kreasi seniman modern Indonesia. Jim Supangkat menjelaskan;"modernitas Indonesia, mengandung pula berbagai aspek yang berakar pada kondisi lokal, seperti kolektivitas, moralitas, spiritualitas, kepercayaan pada mitologi, kepercayaan pada alam, etnisitas, keterikatan pada tradisi dan sebagainya" (Jim Supangkat, 1999). Kondisi yang cenderung berbeda dengan semangat modernisme seperti dijelaskan Paul Mattick (2003) dalam "Some Masks of Modernism" bahwasanya; "the effect of modernity is made all the more striking by its visible contrast with classical tradition".

Keterpisahan yang tegas dengan tradisi seperti dijelaskan Mattick menjadi ciri khas seni rupa Modern. Perkembangan modernitas seperti yang terepresentas pada karya-karya modern Indonesia pameran KIAS dengan nilai modernitas yang berbeda dengan Barat (Eropa dan Amerika) menjadikannya tidak dapat diterima pada konstelasi seni rupa Modern.

Terlebih lagi karya-karya seni rupa yang masih memperlihatkan jejak keterikatan yang erat dengan bahasa rupa tradisi etnik tertentu, pastinya tidak akan pernah dianggap sebagai karya seni dan karena itulah hanya masuk kategori material culture dalam lingkup etnografi. Jika persepsi tersebut masih terus diwarisi dalam perkembangan seni rupa kontemporer, tentunya karya-karya seniman yang telah dikaji dalam pembahasan ini tidak akan bisa diakui sebagai karya seni rupa.

Situasinya jauh berbeda dalam perkembangan seni rupa postmodern atau seni rupa kontemporer, yang mengusung keterbukaan (pluralitas), merangkul berbagai keragaman seni rupa global termasuk praksis-praksis seni rupa yang sebelumnya terpinggirkan dalam dikotomi seni rupa Modern. Runtuhnya dominasi yang absolut seni rupa modern dimulai tandai dengan perkembangan seni postmodern yang mengkritisi dan mengobrak-abrik tatanan dalam mainstream modernisme.

Filsuf dan penulis seni rupa Arthur C. Danto menyatakan dengan the end of art. Hans Belting menyatakan the end of history of art, konotasi the end yang disuarakan oleh kedua penulis berpengaruh tersebut bukan berarti seni rupa telah berakhir. Inti persoalan dari bahasan mereka adalah berakhirnya dominasi yang absolut dari seni Modern dalam menentukan standar nilai yang dalam kenyataannya sangat subyektif. Kondisi postmodern membawa perubahan besar dalam tatanan seni rupa dunia, dimana value of the art (nilai karya seni) kini telah menjadi begitu terbuka, dan tidak lagi absolut ditangan institusi seni rupa modern.

Hal ini ditegaskan oleh Martina Margetts dengan menyatakan; "kalau post-modernisme bisa disebut membawa manfaat, maka manfaat itu dapat dilihat pada perkembangan kriya etnik". Post-modernisme menurut Margetts telah membuka batas-batas seni rupa, desain, dan kriya, yang lama terpaku pada standar konservatif-Modernisme. Kriya dan seni rupa etnik yang sudah lama tersingkir, kini menjadi sumber perkembangan yang penting, Martina menaruh harapan yang besar terhadap kriya untuk bangkit dalam era keterbukaan, yang multikultur dan mangusung pluralitas post-modernisme.

Seni rupa memasuki arena yang sangat terbuka dalam perkembangan kontemporer Julian Stallabrass menyebutnya dengan a zone of fredom, salah satunya adalah menglobalnya mekanisme nilai yang dibentuk oleh institusi pasar atau market value. Dalam institusi pasar seniman dinaungi oleh art management yang mempromosikan dan mencarikan saluran bagi karya seniman, dan didukung oleh modal kapital yang cukup besar bahkan juga didukung oleh konsultan artistik umumnya penulis atau kurator yang mendampingi seniman dalam menggodok ide-ide kreatifnya. 
Karyanya diwacanakan dengan baik dipamerkan pada galeri dengan publikasi yang bagus mulai dari katalog, reviu di media massa dan majalah sen rupa dan sebelumnya publikasi pameran tersebut telah diiklankan pada majalah seni rupa. Dalam mekanisme pasar, yang dipentingkan adalah letupan-letupan sensasional yang dibawa oleh idol-idol baru, dan yang terjadi di Indoesia belakangan ini adalah gejala keseragaman "taste", seperti ditengari oleh Julian Stalabrass bahwa seni rupa kontemporer memperlihatkan kecenderungan "uniformity".

Namun dibalik keterbukaan tersebut perlu dicermati bahwa secara institusional perkembangan seni rupa kontemporer tetaplah mewarisi institusi sen rupa modern dan perkembangan karya-karya seni rupa kontemporer tetap berasal dari tradisi fine art. Sehingga patut dicurigai jangan-jangan mekanisme dalam membentuk nilai seni rupa juga tetap terwarisi. Sehingga muncul pertanyaan; dapatkan seni rupa yang berkembang dari tradisi etnis yang selama ini berada dalam naungan wacana antropologi memasuki wacana seni rupa kontemporer? Untuk menjawabnya, perlu dipertegas kembali bahwa ada sebuah potensi yang terdapat pada perkembangan bahasa rupa tradisi seperti ditunjukkan oleh senimanseniman otodidak yang mengangkat bahasa rupa tradisi.

Meminjam analisis Antony Giddens, yang menjelaskan bahwa; "tradisi tidak sepenuhnya statis, karena ia harus ditemukan ulang oleh setiap generasi baru ketika ia mengambil alih warisan budaya pendahulunya" (Giddens 2005). Perkembangan dalam konteks seni rupa (tradisi) Bali menunjukkan kebenaran pendapat Giddens, kreativitas yang dilakoni oleh para seniman otodidak ini menandakan pemaknaan baru terhadap nilai-nilai tradisi sehingga memiliki relevansi dengan perkembangan zaman.

Dalam konteks global keterbukaan seni rupa kontemporer seperti yang diwacanakan oleh tokoh-tokoh seperti Hans Belting dalam the Global Art Forum, Martina Marget, serta optismisme dalam suasana tumpah ruah postmodern yang Sue Rowley yang menyatakan bahwa; "banyak seniman kontemporer, termasuk juga seniman instalasi dan tekstil, mengunakan "kriya" (kecakapan yang berbasis pada technical knowledge) justru untuk melakukan refleksi kritis atas kondisi sosial".

Berkaca dari wacana tersebut tentunya kita patut optimis dengan potens yang dimiliki oleh bahasa rupa tradisi Bali seperti yang digeluti oleh senimanseniman dalam pembahasan ini, dapat memberi warna yang lebih beragam pada perkembangan seni rupa kontemporer. Mekanisme pasar hanyalah salah salah satu sub dari berbagai macam elemen dalam institusi seni rupa kontemporer seperti art teories yang seharusnya digawangi oleh akademisi, dapat berperan dalam menyeimbangkan wacana supaya tidak didominasi oleh penetrasi sub bidang tertentu semata. Keterlibatan theoritical knowledge dari ranah akademis sangat diperlukan dalam mengangkat potensi bahasa rupa tradisi (Bali) untuk menjadikannya lebih bermakna pada konstelasi wacana seni rupa kontemporer.

\section{PENUTUP}

Tradisi dengan nilai-nilainya tetap bertahan dan sekaligus mengalami dinamika perubahan dan bahkan mengalami rekonstruksi kembali, dalam proses interaksi dengan modernitas. Perkembangan seni rupa Pita Maha menunjukkan proses interaksi tersebut telah terjadi dalam seni rupa Bali sejak tahun 1930-an. Perkembangan tersebut menunjukkan seni tradisional kemudian tumbuh dalam wujud yang baru, dan sekaligus tetap menunjukkan keberlanjutan bahasa rupa tradisional. Seni rupa tradisi di tangan seniman Pita Maha menjelma menjadi seni yang lebih sekuler, tidak lagi sakral untuk persembahan, dan mengalami perkembangan dalam hal teknik, gaya dan tema, dari mitologi Hindu menjadi tema sosial masyarakat. Perkembangan ini menunjukkan tradisi bukan hanya sesuatu yang diwariskan, sebagian dari tradisi adalah hasil sebuah konstruksi dalam kebudayaan. Penguatan tradisi terjadi pada perkembangan sebuah kebudayaan muncul karena pengaruh modernitas beiringan konstruksi kebudayaan dan munculnya kesadaran pada identifikasi diri atau pencarian sebuah identitas budaya.

Kreativitas dalam mempertahan pengetahuan praktis berupa kecakapan teknik dan olah material yang ditampilkan oleh para seniman otodidak Bali, menampilkan betapa seni rupa Bali kaya dengan pengetahuan lokal yang menjadi aset dan potensi yang dapat diangkat ke dalam basis penelitian di wilayah akademis dan juga dapat diangkat ke arena perkembangan wacana seni rupa kontemporer.

Seni rupa dalam kebudayaan Bali diwarisi secara turun menurun menjadi tradisi, dijalani secara berulang-ulang dan terekam dalam ketaksadaran kolektif (colective unsconciusness), menjadi kebiasaan yang dijalani secara otomatis dan berluang-ulang. Para seniman yang telah dibahas pada kajian ini menunjukkan bahwa kreativitas otodidak yang cenderung jauh dari "nilai-nilai akademis" ternyata mampu melampaui ketaksadaran kolektif, mereka dengan sadar melakukan inovasi-inovasi dari bahasa rupa yang dijalani dalam ranah kolektif. Menjadikannya memiliki kekhasan pribadi (identitas) dan tetap mendasarkan pada nilai-nilai yang berasal dari kearifan budaya.

Kepopuleran seni rupa tradisi Bali yang tersohor di luar negeri pada umumnya berada dalam wadah museum etnografi, karya-karya seniman Bali kemudian dimasukkan sebagai kategori artefak kebudayaan (material culture) dan bukan the work of art (karya seni). Dalam konstelasi perkembangan wacana, seni kontemporer membawa semangat pluralitas, tanpa dikotomi pusat-pinggiran, karena berbagai basis perkembangan seni rupa di berbagai wilayah atau lokus 
(negara) mempunyai ruang yang sama untuk mewacanakan sendiri perkembangan medan seni rupa mereka dengan konteksnya masing-masing.

Sebagai sebuah tawaran, wacana post etnic yang kini sedang berkembang dalam wacana global art, dapat menjadi sebuah kesempatan baik bagi seniman yang berkarya dengan basis ide dari kasanah tradisi-etnis untuk menafsirkannya ke dalam karya-karya mereka, dalam konteks perkembangan seni rupa kontemporer. Untuk mendukung hal tersebut, maka diperlukan keterlibatan berbagai pihak dalam upaya rekonstruksi ini, terutama keterlibat para pakar keilmuan yang berada dalam wilayah akademis untuk mendorong upaya tersebut.

\section{DAFTAR PUSTAKA}

Anthony Giddens. 2005. Konsekuensi-Konsekuensi Modernitas, Kreasi Wacana, Yogkarta

Arthur C. Danto. 1997. After the End of Art,Contemporary Art and The Pale of History. Princeton University Press New Jersey

Asmudjo J. Irianto. 2000. Outlet; Yogya Dalam Peta Seni Rupa Kontemporer Indonesia. Yayasan Seni Cemeti Yogyakarta

Christtopher Tilley, et. al. 2006. Handbook of Material Culture, SAGE Publucations Ltd. London

Hans Belting. 1995. The End of the History of Art, dalam Art History and Methods a Critical Antology, Paidon Press Limited

Harward Risatti. 2007. A Theory of Craft, Function and Aesthetic Expression, the University of North Carolina Press, USA

Jim Supangkat. 1999. Pameran Modernitas Indonesia Dalam Representasi Seni Rupa, Galeri Nasional Indonesia Jakarta

Julian Stallabrass. 2004. Contemporary Art, A Very Short Introduction, Oxford University Press New York

Martina Margett. 1998. Pameran Pola Hias Dalam Seni Kontenporer “ Makna yangBerlapis- lapis”, disponsori oleh Asialink, Canberra School of Art Gallery, dan Australian National University

Paul Mattick. 2003. Art in its Time, Routledge, London

Sue Rowley. 2003. Kriya, Kreativitas dan Praktek Kritis, Katalog Cp Open Biennalle 1. Galeri Nasional, Jakarta

\section{EKSPLORASI PEMANFAATAN SENI TRADISIONAL PADA DESA-DESA WISATA DI KABUPATEN SLEMAN}

Enis Niken Herawati, Ari Kusmiyatun, dan Titik Putraningsih Fakultas Bahasa dan Seni Universitas Negeri Yogyakarta

\section{Abstract}

The main purpose of this study is to assess the cultural arts in some villages in Sleman district. In particular, this study aims to: 1) describe the types of traditional arts in tourist villages in Sleman district, 2) describe the presentation of traditional art performed in every tourism village in Sleman district, 3) describe the efforts to preserve the kinds of traditional art which are likely developed in the tourist villages in Sleman district. The results reveal that in some developing tourist villages there are many traditional art forms such as dance, traditional music (gamelan), puppet art, traditional games for children, with their own kind of variety. Art traditions in rural tourism are presented in a simple way and yet touched with good aesthetic arts that are still hereditary. The presentation of a certain kind of art attractions is based on the demand of visitors, but some are conducted based on the initiative coming from the tourist village manager. The traditional art in the main tourist village is used to attract visitor to come. It is also used as a venue for traditional art reception, entertainment, cultural recognition, the regeneration of art activists, and community empowerment.

Keywords: exploration of utilization, traditional arts, rural tourism

\section{PENDAHULUAN}

Seni dan budaya adalah dualisme yang sangat erat berkaitan. Seni merupakan suatu ekspresi jiwa manusia yang tertuang dalam berbagai bentuk karya. Sementara budaya menjadi suatu kekayaan masyarakat yang hadir dari pola bentukan masyarakat yang bersangkutan (termasuk karya seninya). Dari masa ke masa, seni selalu menjadi satu fenomena yang memiliki pengertian yang hybrid. Artinya setiap individu berhak memiliki pengertian masing-masing terhadap seni, namun semua teori dan pengertian itu harus berdasarkan alasan yang jelas dan telah disepakati oleh suatu komunitas. Yang terpenting dalam hal ini adalah bahwa seni memiliki muatan edukatif yang bisa ditransformasikan ke dalam kehidupan sehari-hari. 